\title{
Study of prescribing pattern of drugs used in the treatment of bronchial asthma at tertiary care hospital of northern India
}

\author{
Garima Adhaulia $^{1 *}$, Divya Singh ${ }^{1}$, Suryakant $^{2}$, Ajay Verma ${ }^{2}$, Arpita Singh ${ }^{3}$, \\ Rajendra Nath ${ }^{1}$, Amod K. Sachan ${ }^{1}$, Rakesh K. Dixit ${ }^{1}$
}

\author{
${ }^{1}$ Department of Pharmacology and Therapeutics, ${ }^{2}$ Department of Respiratory Medicine, King George's Medical \\ University, Lucknow, Uttar Pradesh, India \\ ${ }^{3}$ Department of Pharmacology, Dr. Ram Manohar Lohia Institute of Medical Sciences, Lucknow, Uttar Pradesh, India
}

Received: 20 November 2019

Revised: 29 December 2019

Accepted: 02 January 2020

\section{*Correspondence:}

Dr. Garima Adhaulia,

Email: drgarima.26@gmail.com

Copyright: (C) the author(s), publisher and licensee Medip Academy. This is an open-access article distributed under the terms of the Creative Commons Attribution Non-Commercial License, which permits unrestricted non-commercial use, distribution, and reproduction in any medium, provided the original work is properly cited.

\begin{abstract}
Background: Asthma is a chronic inflammatory disease requiring long term treatment. For an effective control of asthma symptoms background knowledge of the prescribing pattern of anti-asthmatic drugs is a must.

Methods: A prospective, observational study was conducted in the Department of Respiratory Medicine OPD, King George's Medical University, Lucknow. 114 patients of asthma were recruited for the study. A case report form was filled from patient's prescription containing the demographic details of the patients, presenting complaints, investigations and drugs prescribed along with their dose, duration, frequency, route of administration.

Results: 114 patients' prescriptions were assessed which showed average number of drugs per prescription - 3.22. $42.8 \%$ and $50 \%$ of the drugs were prescribed in accordance with World Health Organization model list of essential medicines and National list of essential medicines. Short acting $\beta 2$ agonist (salbutamol), 61.4\% was the most commonly and frequently prescribed single anti asthmatic drug. Combination of inhaled corticosteroid and long acting $\beta 2$ agonist, $86.8 \%$ was the most commonly prescribed fixed dose combination anti asthmatic drug. Inhalational route $(75 \%)$ was the most preferred one over oral route $(25 \%)$.

Conclusions: Asthma being a chronic disease requires prolonged treatment which imposes economic burden on the patients. Judicious prescription of drugs not only improves the patient clinically but also removes the unnecessary burden. Data obtained from these studies can be used as a guide to make future decisions regarding standard prescription.
\end{abstract}

Keywords: Asthma, Prescription pattern, Anti-asthmatic drug, Rational use of drugs

\section{INTRODUCTION}

According to World Health Organization (WHO) asthma is defined as a chronic inflammatory disease of the airways characterized by bronchial hyper-responsiveness and airflow limitation leading to asthma symptoms of varying frequency and severity over time. Global Asthma Report (2018) says that approximately 339.4 million people are affected worldwide and the prevalence increases by $50 \%$ every decade. ${ }^{1}$ In India about $15-20$ million people are affected by asthma. ${ }^{2}$ Although the disease can affect all extremes of ages but the prevalence is seen high among children and adolescents with an estimated range of 3 to $38 \%$ and 2 to $12 \% .^{3}$

Prescribing pattern studies as a part of drug utilization studies, plays crucial role in promoting and practicing rational use of medicines. Rational use of drugs is defined 
as providing medications in appropriate dose, duration, frequency, indication, patients, and at appropriate cost the community can afford. ${ }^{4}$ Prescription patterns explains about the pattern and extent of drug use, quality of drugs prescribed, compliance with regional, state or national guidelines like standard treatment guidelines, usage of drugs from essential medicine list and use of generic drugs. ${ }^{5}$ These studies helps us in analysing the rationality of drug use and avoiding irrational prescriptions which are contributing to the unnecessary cost of the treatment which in turn decreases patients compliance and its adherence towards treatment. WHO core prescribing indicators were included in these studies and are modified according to objective of the study. The pattern of drug prescription varies tremendously in different countries of the world as well as in the different regions of the same countries. For a cost-effective control of asthma, it is necessary to prescribe drugs in accordance with the guidelines on asthma management. There have been growing importance of these studies because of the concern regarding irrational prescriptions, various new drugs in the market for a particular treatment, delayed adverse effects due to drugs and ultimately unnecessary increased cost of treatment. ${ }^{6}$ The present objective of the study is to evaluate the prescribing pattern of drugs used in the treatment of asthma patients attending Respiratory Medicine OPD of King George's Medical University, Lucknow.

\section{METHODS}

The present prospective, observational study was conducted in the Department of Pharmacology and Therapeutics, King George's Medical University, Lucknow in collaboration with Department of Respiratory Medicine OPD, King George's Medical University, Lucknow from November 2018 to August 2019. The study was started only after getting the ethical approval from the Institutional Ethics Committee of King George's Medical University, Lucknow. Total 114 patients who were diagnosed with asthma as primary disease were recruited after fulfilling our inclusion exclusion criteria. In this study we attempted to evaluate the prescribing trend of anti-asthmatic drugs in asthma patients. WHO core prescribing indicators were taken into consideration in evaluating the rationality of prescriptions.

\section{Inclusion criteria}

All patients diagnosed with bronchial asthma; either male or female; patients within the age limit of 18 and above, patients willing to get enrolled in a study with consent were included.

\section{Exclusion criteria}

Patients who are less than 18 years; patients not willing to participate or give consent; those patients who are not able to give interview; patients with associated co- morbidities such as hypertension (HTN), diabetes, heart diseases, tuberculosis (TB), HIV-AIDS; concurrent major psychiatric illness and/or concurrent major medical illness; patient with chronic illness and terminally end stage patients were excluded.

The procedure followed in this observational study was in agreement with the ethical standards of the authority committee on human experimentation (Institutional or national). Detailed history, signs and symptoms, physical examination and investigations like pulmonary function tests - spirometry, absolute eosinophilic count (AEC) and serum IgE levels were done to confirm the diagnosis of asthma. Data from the records were entered into a specially designed case report from (CRF) which included patients demographic details (patients name, age, sex, occupation, residence, OPD registration number), presenting complaints and their duration, history of cigarette smoking, family history of asthma, any previous treatment history or current treatment, associated comorbidities (such as HTN, Diabetes, TB, AIDS, heart disease etc), investigations related to diagnosis (mainly spirometry which was performed using spirometer (pulmonary function equipment) of Cosmed company for evaluation of forced vital capacity (FVC), forced expiratory volume at 1 minute $\left(\mathrm{FEV}_{1}\right), \mathrm{FEV}_{1} / \mathrm{FVC}$ ratio. Drugs prescribed for asthma along with dosage, duration, frequency and route of administration. On confirming the diagnosis of asthma, the prescriptions forms were collected from the patient and relevant information satisfying the objective of the study were noted on the CRF. The patients were followed up at $4^{\text {th }}$ week ( 1 month) and $12^{\text {th }}$ week ( 3 month) and 6 months for clinical improvement and for any additional medication. The data obtained from the prescription regarding prescription of anti-asthmatic drugs was assessed and evaluated using appropriate statistical tests on completion of the study.

Pattern of anti-asthmatic drugs used in the study was analyzed using WHO core prescribing indicators. These indicators were adopted and modified as per the objective of the study.

\section{Statistical analysis}

Data were analyzed using Statistical Package for Social Sciences (SPSS) version 21.0. Categorical variables are presented in number and percentages $(\%)$ and mean \pm SD. Data and results were represented in suitable graphical and tabular forms.

\section{RESULTS}

\section{Prescribing pattern indicators}

Prescribing indicators were used to evaluate the rationality of drugs prescribed in the treatment of bronchial asthma. 


\section{Drug use indicators}

Average number of anti-asthmatic drugs encountered per prescription were 3.22 and only $46 \%$ of the drugs were prescribed by generic names. Prescriptions were further assessed for their consistency with WHO model list of essential medicines $21^{\text {st }}$ list 2019 and national list of essential medicines 2015 (NLEM 2015) and it was found that $42.8 \%$ and $50 \%$ of the drugs were prescribed from them which are as shown in Table 1 and 2.

Table 1: WHO core prescribing indicators.

\begin{tabular}{|ll|}
\hline Indicators & Result \\
\hline Average number of drugs per prescription & 3.2 \\
\hline Percentage of drugs prescribed by generic name & $46 \%$ \\
\hline Percentage of encounters with an antibiotic prescribed & $81.4 \%$ \\
\hline Percentage of drugs prescribed from essential drugs list & WHO EDL - 42.8\%, NLEM - 50\% \\
\hline
\end{tabular}

WHO EDL: WHO essential drug list.

Table 2: List of anti-asthmatic drugs in WHO EDL, NLEM.

\begin{tabular}{|llllll|}
\hline Total no. of anti-asthmatic drugs & \multicolumn{2}{l|}{ No. of drug belonging to } & \multicolumn{2}{l|}{ of drug belonging to } \\
\hline WHO EDL & NLEM & WHO EDL & NLEM & WHO EDL & NLEM \\
\hline 7 & 6 & 3 & 4 & 42.8 & 50 \\
\hline
\end{tabular}

Table 3: Class of anti-asthmatic drugs used.

\begin{tabular}{|ll|}
\hline Class of drug & Drugs used \\
\hline Short acting $\boldsymbol{\beta 2}$ agonist (SABA) & Salbutamol \\
\hline Long acting $\boldsymbol{\beta 2}$ agonist (LABA) & Formoterol, Salmeterol \\
\hline Corticosteroids & Budesonide, Fluticasone, Prednisolone, Methylprednisolone \\
\hline Methylxanthines & Doxophylline, Ace-brophylline, Etofylline, Theophylline \\
\hline Anticholinergics & Tiotropium Bromide, Ipratropium Bromide \\
\hline Leukotriene modifiers & Montelukast \\
\hline Anti-histamines & Levocetrizine, Fexofenadine, Desloratide, Azelastine \\
\hline
\end{tabular}

Table 4: Other class of drugs prescribed along with anti-asthmatic medications.

\begin{tabular}{|lll|}
\hline Therapeutic class & Drugs used & $\begin{array}{l}\text { Number of prescriptions } \\
\text { N (\%) }\end{array}$ \\
\hline Mucolytic agents & Ambroxol, acetylcysteine & $20(17.5)$ \\
\hline Expectorant & Guainefenesin & $12(10.5)$ \\
\hline Antitussive & Dexomethorphan & $4(3.5)$ \\
\hline Antacids & $\begin{array}{l}\text { Esmoprezole, omeprazole, rabiprazole, } \\
\text { pantoprazole }\end{array}$ & $18(15.7)$ \\
\hline Antiemetic & Domperidone & $2(1.7)$ \\
\hline Vitamin minerals antioxidants & $\begin{array}{l}\text { Vitamin A, D, E, B complex, selenium, zinc, } \\
\text { copper }\end{array}$ & $45(39.4)$ \\
\hline Calcium supplements & Cholecalciferol, calcium carbonate, vitamin & $3(2.6)$ \\
\hline Iron supplements & D3 & $5(4.3)$ \\
\hline NSAIDs & Ferrous ascorbate, ferrous sulphate & $8(7.01)$ \\
\hline
\end{tabular}

Antibiotics were given mainly to treat secondary respiratory tract infections and $81.4 \%$ of them were prescribed in 93 prescriptions. The most commonly prescribed antibiotic was azithromycin (61.4\%) followed by cefpodoxime proxetil alone $(7.8 \%)$ and in combination with clavulanic acid (7.8\%) while others antibiotics prescribed contributed $4.4 \%$. Graphical distribution of them were shown in Figure 1.

According to the guidelines for the management of asthma, the common class and drugs used in the study population are presented in Table 3 . Other class of drugs
(Table 4) prescribed along with anti-asthmatic drugs showed that multi-vitamins (39.4\%), mucolytic agents (17.5\%), proton pump inhibitors (antacids) (15.7\%), expectorant (10.5\%) and NSAIDs (7.01\%) were prescribed as adjuvant therapy. Mucolytic agents and expectorants were mainly given in syrup forms for symptomatic relief.

\section{Pattern of drug therapy of anti-asthmatic medications}

In this study, out of 114 patients, 8 (7.02\%), $72(63.16 \%)$ and $34(29.82 \%)$ patients were prescribed two, three and 
four drug therapy and none of them were on single drug therapy as asthma patients requires multiple therapy for symptomatic relief. The utilization pattern of different anti-asthmatic drugs according to the type of therapy were shown in the Table 5.

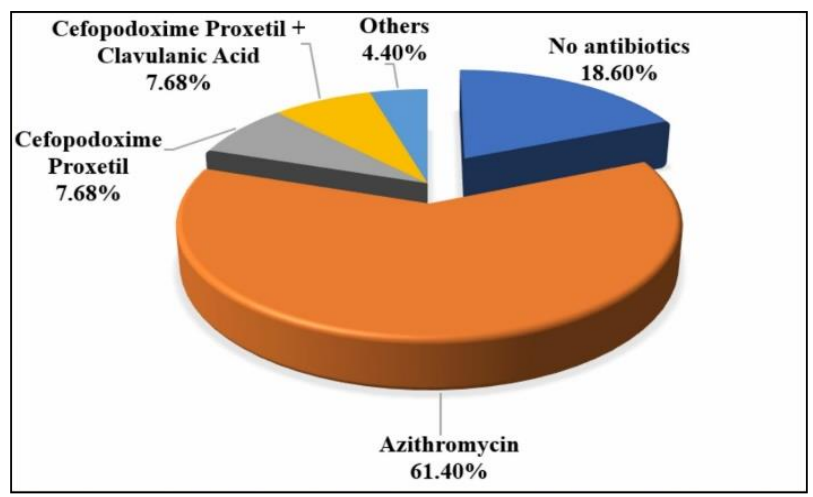

Figure 1: Distribution of prescribed antibiotics.

Table 5: Drug therapy regimen.

\begin{tabular}{|l|l|}
\hline $\begin{array}{l}\text { Pattern of drug } \\
\text { therapy }\end{array}$ & $\begin{array}{l}\text { Number of prescriptions } \\
\text { N }(\%)\end{array}$ \\
\hline Two drugs & $8(7.02)$ \\
\hline Three drugs & $72(63.16)$ \\
\hline Four drugs & $34(29.82)$ \\
\hline
\end{tabular}

Types of anti-asthmatic medications prescribed according to their classes

SABA (salbutamol - 61.4\%) was the most commonly and frequently prescribed single anti asthmatic drugs followed by methylxanthines $(28.9 \%)$, corticosteroids $(9.6 \%)$, anticholinergics (7\%) and anti-histaminics $(0.87 \%)$ as shown in Table 6.

Table 6: Commonly prescribed single class of antiasthmatic drug.

\begin{tabular}{|l|l|}
\hline Drugs & $\begin{array}{l}\text { Number of prescriptions } \\
\mathbf{N}(\%)\end{array}$ \\
\hline SABA ( $\beta 2$ agonist) & $70(61.4)$ \\
\hline Anticholinergic & $8(7)$ \\
\hline Methylxanthines & $33(28.9)$ \\
\hline Corticosteroids & $11(9.6)$ \\
\hline $\begin{array}{l}\text { Antiallergic } \\
\text { (antihistaminics) }\end{array}$ & $1(0.87)$ \\
\hline
\end{tabular}

Majority of the patients were on fixed dose combination (FDCs). Most commonly prescribed FDC of antiasthmatic drug is combination of steroid (ICS) and LABA $(86.8 \%)$. Out of which, the most common combination used is budesonide and formeterol $(78.95 \%)$ as shown in Table 7.

Inhalational route $(75 \%)$ was the most preferred one over oral route $(25 \%)$ as shown in Table 8 .
Table 7: Prescribed FDCs of anti-asthmatic drugs.

\begin{tabular}{|l|l|}
\hline Drugs & $\begin{array}{l}\text { Number of } \\
\text { prescriptions }\end{array}$ \\
\hline N $(\%)$
\end{tabular}

Table 8: Different dosage forms used by asthmatic patients.

\begin{tabular}{|ll|}
\hline Oral (\%) & Inhalational (\%) \\
\hline 25 & 75 \\
\hline
\end{tabular}

\section{DISCUSSION}

Bronchial asthma is a major global public health problem resulting in significant morbidity and mortality. Chronic nature of the disease requires prolong treatment which further increases the cost of therapy and reduces patient's adherence. Importance of prescription pattern monitoring studies sets in for obtaining data about the patterns and rationality of drug use. In developing countries irrational use of drugs and prescription are the major emerging problem. So, in current scenario where scarcity of resources increases out of pocket expenditure, rational prescription and cost-effective treatment is indispensable for better compliance and healthy outcome both medically and economically. In this study, average number of drugs prescribed per prescription were 3.22 which is in accordance with studies by More et al and Rajathilagam et al showed comparable results of 3.82 and 3.63 as the average number of drugs per prescription. ${ }^{7,8}$ Rafeeq et al also reported average number of drugs per prescription as 3.18. ${ }^{9}$ While Micheal et al and Triveni et al found to have 5.951 and 4.75 as average drugs per prescription. ${ }^{10,11}$ The number of drugs per prescription should be kept as minimum as possible in order to avoid drug or drug interactions and unnecessary economic burden on the patient. This trend in drug prescription may be attributed to the fact that drugs that more drugs are prescribed to provide symptomatic relief rather than asthma control.

$46 \%$ drugs were prescribed with generic names. However, the percentage of prescribing by only generic names was found very low $(3.6 \%)$ in Trivedi et al study whereas it was found encouraging in More et al study which showed that $74.2 \%$ drugs were prescribed by generic names. ${ }^{7,11}$ Decreased number of prescription of generic drugs may be attributed to the non- availability of the generic version of the branded drugs available in the market and also if 
generic counterparts available might be less effective clinically. Essential drugs fulfill the basic health care needs of the population, available at a price affordable for the society and offers cost effective solution to many health related problems. ${ }^{12} 42.8 \%$ and $50 \%$ of drugs were prescribed from WHO model list of essential medicines $21^{\text {st }}$ list 2019 and national list of essential medicines of India 2015 which was low as compared to that reported by More et al study where $99.6 \%$ prescriptions were from NLEM 2015 which is in accordance with standard values (100\%) of percentage of drugs prescribed from the essential drug list or formulary. ${ }^{7}$ The low value in the study may be due to lack of adherence to prescribing from essential drug list.

81.4\% antibiotics were prescribed along with antiasthmatic drugs. On the similar trend Puranik et al, Rajathilagam et al study showed the use of $91.2 \%$ and $65.6 \%$ antibiotics which is comparable with our study. ${ }^{8,13}$ However, Michael et al, More et al, Trivedi et al studies have shown $35.3 \%, 25 \%, 17.3 \%$ use of antibiotics along with other anti-asthmatics. ${ }^{7,10,11}$ Most commonly prescribed antibiotic was azithromycin $(61.4 \%)$ followed by cefpodoxime proxetil alone $(7.8 \%)$ or in combination with clavulanic acid (7.8\%). More use of antibiotics may be attributed to high effectiveness of antibiotics against bronchial hyper-responsiveness with underlying respiratory tract infections. ${ }^{14,15}$

Levosalbutamol -SABA (61.4\%) was the most commonly and frequently prescribed single class of anti-asthmatic drug. The result of our study are in favour of findings of other studies by More et al, Rafeeq et al, Rajathilagam et al also showed SABA as the most commonly prescribed single group. ${ }^{7-9}$ However, study by Trivedi et al have shown methylxanthines $(93.5 \%)$ as the most commonly prescribed single class anti-asthmatic. ${ }^{11}$ Other than short acting $\quad \beta 2$ agonists, methylxanthines (28.9\%), corticosteroids $9.6 \%$ ), anticholinergics $(7 \%)$ were also prescribed. SABA are highly preferred for asthma because of its easy availability, fewer side effects and cost effectiveness. They also relax airway smooth muscle, inhibit release of mediators from mast cells that cause bronchoconstriction, inhibit microvascular leakage and increase muco-ciliary transport by increasing ciliary activity.

Among FDCs therapy, most commonly prescribed anti asthmatic FDCs was corticosteroid (ICS) and LABA $(86.8 \%)$. Out of which, the most common combination used was budesonide and formoterol (78.95\%). Second most common combination used was montelukast and levocetrizine $(73.68 \%$ ) which is comparable to studies by Trivedi et al, Rajathilagam et al showed similar trends. Analysis suggested that doctors preferred inhalational preparations over the oral formulations as bioavailability of inhalation preparations are maximal, with rapid mode of action providing immediate relief and require smaller doses. ${ }^{8,11}$ In present study the most common route of administration is inhalational route $(75 \%)$ which is comparable with studies Puranik et al, Rafeeq et al which showed similar results. ${ }^{9,13}$

Limitations of the study was its short duration of 10 months only and small sample size of 114 were considered for analysis and that may not have been representative of the patient population. Other variables such as concurrent medications, comorbid conditions etc may influence anti-asthmatic drug behaviour. However, these variables were not considered in the present study. Further studies with larger sample size and longer duration of study will give us better insight regarding prescription writing practices. Such type of studies provides necessary feedback to prescribers and may prove useful to formulate guidelines to policy makers. This study has dealt with the basic concept and identified key areas that require modifications for rational use of drugs.

\section{CONCLUSION}

Drug prescriptions for asthma patients were rational regarding their doses, duration and route of administration. Further efforts must be made to encourage more and more prescription of generic drugs according to guidelines for asthma management. In government set up patient load is very high, so there is a need to sensitize health professionals to promote judicious use of different classes of drugs to avoid un-necessary use as well as drug interactions. Based on the results, it was observed that most of the patients were prescribed with multiple (two, three, four) drug therapy, out of which inhalational route was the most preferred one. Anti-asthmatic drugs given as inhalational therapy are more beneficial to the patients than systemic therapy. Most frequently prescribed single class anti-asthmatic drug was levosalbutamol (SABA). Combination (FDCs) of ICS and LABA was the most commonly prescribed FDC. In the present study there is enormously higher use of antibiotics $(81.4 \%)$ which raises serious concern regarding its judicious use.

\section{ACKNOWLEDGEMENTS}

I acknowledge all my co-authors for their contribution in the research work.

\section{Funding: No funding sources}

Conflict of interest: None declared

Ethical approval: The study was approved by the Institutional Ethics Committee, K.G.M.U., Lucknow

\section{REFERENCES}

1. Global Asthma Network. The Global Asthma Report. 2018. Available at: http://www.globalasthma report.org/Global\%20Asthma\%20Report\%202018. pdf. Accessed on 8 September 2019.

2. Kant S. Socioeconomic dynamics of asthma. Indian $\mathbf{J}$ Med Res. 2013;138(4):446-8.

3. Cavkaytar O, Sekerel BE. Baseline management of asthma control. Allergol Immunopathol (Madr). 2014;42:162-8. 
4. WHO. The Pursuit of Responsible Use of Medicines: Sharing and Learning from Country Experiences. Essential medicines and health products.Rational use of medicines. WHO. 2015. Available at: https://www.who.int/medicines/areas/rational_use/en. Accessed on 4 September 2019.

5. Jain S, Upadhyaya P, Goyal J, Kumar A, Jain P, Seth $\mathrm{V}$, et al. A systematic review of prescription pattern monitoring studies and their effectiveness in promoting rational use of medicines. Perspect Clin Res. 2015;6(2):86-90.

6. Bosu WK, Ofori-Adjei D. An audit of prescribing practices in health care facilities of the Wassa West district of Ghana. West Afr J Med. 2000;19:298-303.

7. More SR, Dabhade SS, Ghongane BB. A Prospective Study of Evaluation of Medical Prescriptions And Drug Utilization For Bronchial Asthma Patients At A Tertiary Care Hospital. IOSR J Dental Medical Sciences. 2017;16(11):37-43.

8. Rajathilagam $\mathrm{T}$, Sandozi $\mathrm{T}$, Nageswari AD, Paramesh P, Jamuna R. Drug Utilisation Study In Bronchial Asthma In A Tertiary Care Hospital. Int Jf Pharm Applications. 2012;3(2):297-305.

9. Rafeeq MM, Murad H. Evaluation of drug utilization pattern for patients of bronchial asthma in a government hospital of Saudi Arabia. Niger J Clin Pract. 2017;20:1098-105.

10. Michael B, James N, Sreena S, Sindhuja K, Nanjwade BK. Drug Utilization Evaluation Of
Bronchial Asthma In Tertiary Care Hospital. World J Pharmacy Pharma Sci. 2016;5(2):1075-91.

11. Trivedi N. Prescribing pattern in patients of asthma visiting outpatient departments of a tertiary care hospital: a cross-sectional, observational study. Int $\mathbf{J}$ Basic Clin Pharmacol. 2017;6(3):587-91.

12. Simpson GB, Choudary GN. Comparative Analysis of Prescription Writing by Teaching and Non Teaching Clinicians in and around Guntur. Int $\mathbf{J}$ Recent Trends Sci Tech. 2012;5(2):100-3.

13. Puranik A, Totade S. Drug utilization study of bronchial asthma in adults at rural hospital. Int $\mathbf{J}$ Basic Clin Pharmacol. 2019;8:120-7

14. Chesnutt MS, Gifford AH, Prendergast TJ. Asthma. In: Current Medical Diagnosis and Treatment 49th edition.McGraw-Hill, 2010: 216-240.

15. Tripathi KD. Drugs for cough and bronchial asthma, Essentials of Medical Pharmacology. 7 th Edition, New Delhi JAYPEE Brothers Med Publishers. 2013: 218-231.

Cite this article as: Adhaulia G, Singh D, Suryakant, Verma A, Singh A, Nath R, et al. Study of prescribing pattern of drugs used in the treatment of bronchial asthma at tertiary care hospital of northern India. Int J Basic Clin Pharmacol 2020;9:322-7. 